\title{
Divergências e convergências quanto ao conceito de "família" no semanário católico O São Paulo
}

\author{
Fabio Lanza \\ Professor Doutor da Universidade Estadual de \\ Londrina, Londrina, Paraná, Brasil \\ lanza1975@gmail.com
}

Raíssa Regina Brugiato Rodrigues Mestranda pela Universidade Estadual de Londrina, Londrina, Paraná, Brasil raissaregina.uel@hotmail.com

José Wilson Assis Neves Junior Doutorando pela Universidade Estadual Paulista, Marília, São Paulo, Brasil nevesjr1991@gmail.com

Resumo Os debates nacionais atuais acerca do conceito de família suscitaram este artigo, que destacou o campo católico, especificamente a partir do jornal semanário católico $O$ São Paulo - JOSP, órgão oficial da Arquidiocese paulistana, a maior do Brasil. A pesquisa identificou as convergências e as divergências a respeito dos posicionamentos ideológicos que trataram o conceito de "família" com base na compreensão e na interpretação das publicações do JOSP.A fonte documental foi analisada a partir de dois recortes temporais distintos, o das matérias vetadas pela censura prévia da ditadura militar na década de 1970 e as publicações do semanário em 2015, quando a temática se tornou emergente na agenda nacional. Foram identificadas diferenças entre os temas abordados e os discursos das matérias no que tange a relações de gênero, casamento homoafetivo e adoção, entre outros. No entanto, identificamos a mesma perspectiva em relação à defesa da composição chamada de "família tradicional".

Palavas-Chave: Sociologia das religiões, família, Ditadura Militar (1964-1985), Jornal O São Paulo. 


\section{Introdução ${ }^{1}$}

As religiões e as religiosidades estão presentes no cotidiano brasileiro em diversos aspectos: costumes, feriados, formas de conceber determinados fatores da realidade social, das vivências, entre outras características que fazem parte da cultura brasileira. ${ }^{2}$ Por essa razão, pode-se inferir que sua esfera de influência pode abranger, de variadas formas, diferentes elementos nas vidas dos indivíduos e em seu cotidiano, ${ }^{3}$ mesmo daqueles que não compartilham das mesmas religiões, ou, ainda, de alguma forma de crença nesse sentido.

Considerando essa presença (apesar das diferenças na vivência, na espiritualidade e adesão ou não dos indivíduos), que se expressa em processos e relações sociais e culturais, em manifestações, interações, relações sociais, evidencia-se a importância de seu estudo como objeto de pesquisa das Ciências Sociais. ${ }^{4}$

Partindo do pressuposto apresentado por Aquino (2011) de que as religiões têm entre suas características a produção de discursos de verdade e de condutas, articulando modos de subjetividade e concepções sobre a realidade, propõe-se abordar o conceito de "família" vinculado ao campo católico, apresentado nas publicações do jornal O São Paulo (JOSP), ${ }^{5}$ meio de comunicação oficial da Arquidiocese de São Paulo, sede de maior expressão do catolicismo brasileiro.

1 A presente pesquisa foi desenvolvida pela equipe do Laboratório de Estudos sobre as Religiões e Religiosidades da UEL (LERR - UEL/PR). Foi fomentada com recursos do CNPq, CAPES e Fundação Araucária entre os anos de 2014 e 2016.

2 Maduro (1981) observa que as religiões estão ligadas a idiomas, contextos históricos, culturais, sociais e geográficos, variando entre as sociedades, classes sociais e grupos de indivíduos e engendrando crenças, dependências e comportamentos sociais.

3 Um exemplo seria a frase "Deus seja louvado" nas cédulas monetárias brasileiras, a presença de um crucifixo no Supremo Tribunal Federal (STF) ou o não reconhecimento do casamento homoafetivo por integrantes da bancada cristã, ligada à proposta do Estatuto da Família, e feriados de caráter religioso, como o Natal e Páscoa.

4 É importante abordar tal temática no Brasil, considerando também os dados divulgados no Novo Mapa das Religiões (Neri, 2011), no qual 89\% da população brasileira destaca a importância da religião, enquanto $50 \%$ da população frequenta cultos religiosos de diferentes credos.

5 As matérias vetadas constam no acervo digital disponibilizado na obra "Estudos sobre Religiosidades e Mídia Religiosa”. Disponível em: <http://www.uel.br/grupo-pesquisa/socreligioes/pages/ paginas-censuradas-d-o-sao-paulo.php>. Acesso em: 4 mar. 2018. 
Tendo em vista que o catolicismo já foi a religião oficial do país ${ }^{6}$ e continua possuindo o maior número de adeptos ${ }^{7}$ brasileiros, destaca-se a relevância de versar sobre uma percepção de família ligada ao "universo católico". A presente pesquisa propõe, então, abordá-la na forma como é veiculada no meio de comunicação oficial da referida Arquidiocese, considerando as contribuições de Prandi (1975) no sentido de que, no que tange ao catolicismo, encontra-se na família o núcleo de manutenção da fé cristã, das práticas de iniciação e da manutenção da própria instituição religiosa. Para o autor, a legitimação dessas concepções pautadas na religião, configura "processo de internalização de valores que fornecem consciência de significado cristão a condutas específicas criadas pela dinâmica da realização do sistema social" (Prandi, 1975, p. 10).

Com base na recente disponibilização do arquivo de matérias censuradas do jornal católico JOSP, cujo material foi cedido pela Arquidiocese de São Paulo ao projeto de pesquisa "As matérias censuradas do semanário o São Paulo na ditadura militar (19641985)", o que possibilitou a digitalização das matérias e a elaboração de um arquivo documental pelo Núcleo de Documentação e Pesquisa Histórica da Universidade Estadual de Londrina - PR, e a crescente efervescência no que se refere aos debates atuais relacionados à temática família, propõe-se buscar fundamentos teóricos que abordem a relação entre o conceito de família pertinente à perspectiva apresentada a partir do JOSP e os debates atuais, considerando que, no ano de 2015, o tema foi abordado pelo jornal em diversas ocasiões e com diferentes enfoques. Por exemplo:

A próxima assembleia do Sínodo vai, certamente, partir de novo da situação atual da família, sobretudo daqueles desafios já levantados no ano passado e que se referem às mudanças culturais e antropológicas, ao contexto socioeconômico e também eclesial e religioso, que incidem sobre a família e desafiam a evangelização. (Alberto, 2015, p. 23).

É significativo o fato de o tema do Sínodo dos $\operatorname{Bispos}^{8}$ de 2015 ter abordado justamente as famílias e versar também acerca de sua constituição, uma vez que esse debate ganhou destaque por ocasião da proposta e votação do projeto de Lei nº 6583/13,

6 De acordo com Wachholz (2011), tal fator se estendeu desde a invasão colonizadora no ano de 1500 até o final do século XIX.

7 Teixeira (2005) destaca, considerando o censo demográfico realizado em 2000, um declínio no número de adeptos do catolicismo no Brasil. Não deixa de destacar, porém, como é ampla e diversa a religião e suas formas de religiosidade ainda são no país. Ainda, sobre o Censo de 2010, o IBGE afirmou: "Os resultados do Censo Demográfico 2010 mostram o crescimento da diversidade dos grupos religiosos no Brasil. A proporção de católicos seguiu a tendência de redução observada nas duas décadas anteriores, embora tenha permanecido majoritária” (IBGE, 2012). Disponível em: $<$ https: $/ /$ censo2010.ibge.gov.br/noticias-censo id $=3 \&$ idnoticia $=2170 \& v i e w=$ noticia $>$. Acesso em: 4 mar. 2018.

8 De acordo com Konings (2009), o Sínodo dos Bispos é uma instituição permanente criada pelo Concílio Vaticano II para manter "o diálogo dos pastores-bispos das Igrejas particulares” (Konings, 2009, p. 165). Disponível em: <http://faje.edu.br/periodicos/index.php/perspectiva/article/ view/10>. acesso em: 7 jan. 2016. 
o Estatuto da Família. Esta lei a compreende como a união entre um homem e uma mulher por meio do casamento ou união estável ou, ainda, formada por um destes e seus descendentes. ${ }^{9}$ Ou seja, o Estado, que, no caso brasileiro, é oficialmente laico, passaria a instrumentalizar uma definição que apresenta conexões, considerando o posicionamento dos próprios deputados, com concepções religiosas de matriz cristã. ${ }^{10}$

A metodologia adotada para este trabalho consiste em pesquisa qualitativa de caráter documental e pesquisa bibliográfica, visando analisar as convergências e as divergências sobre a concepção de “família” apresentada pelo clero responsável pela elaboração do JOSP na década de 1970 (com base no arquivo de matérias censuradas) e na contemporaneidade (com edições publicadas no decorrer de 2015), visto que foram frequentes por ocasião do Sínodo dos Bispos, realizado em outubro de 2015, cuja temática foi: A Vocação e a Missão da Família na Igreja e no Mundo Contemporâneo.

A pesquisa bibliográfica buscou, além das considerações teóricas e históricas para a análise, a contextualização dos períodos analisados (a Ditadura Militar no Brasil [19641985] e a atualidade), esclarecimentos sobre o catolicismo brasileiro e suas divisões internas, abordar o caráter sócio-histórico e cultural da percepção das famílias como um modelo constituído por pai, mãe e filhos, e versar sobre a importância da perspectiva de família para a religião católica.

A pesquisa com fontes documentais, por sua vez, baseada nas considerações de Cellard (2008), buscou, para a análise, considerar elementos referentes aos que os responsáveis pela edição do JOSP procuraram passar para os leitores em relação à concepção de família. Esses elementos podem ser apreendidos pelas publicações, pelas pessoas para as quais as publicações são destinadas, no caso, o seu público leitor, e pelo contexto social global no qual o documento foi produzido, elementos referentes à conjuntura política, social e cultural que propiciaram a produção do documento em dado momento histórico.

A metodologia utilizada para trabalhar com o material selecionado, de forma intencional a partir do universo proposto,também demandou um processo de categorização, que consiste, de acordo com Fonseca Júnior (2009), em "um trabalho de classificação e reagrupamento das unidades de registro em um número reduzido de categorias com o objetivo de tornar inteligível a massa de dados e sua diversidade" (p. 298). Portanto, elaboraram-se três categorias analíticas, a fim de orientar a seleção e a interpretação dos documentos, que são apresentadas e desenvolvidas ao longo da análise.

É importante observar que o material teórico selecionado para esta pesquisa também aborda, de forma ampla, as características e contornos que a religião católica assume no contexto brasileiro, seus aspectos sociais, culturais e históricos, além das características que

9 Disponível em: <http://www.camara.gov.br/proposicoesWeb/prop_mostrarintegra?codteor=115 9761\&filename=PL+6583/2013>. Acesso em: 28 fev. 2018.

10 Um exemplo da presença da religião em âmbito governamental pode ser observado em entrevista realizada pelo programa Custe o que Custar, com deputados federais comentando o estatuto da família e sua relação com princípios religiosos. Disponível em: < https://www.youtube.com/ watch? $\mathrm{v}=\mathrm{QradxddVrx8>}$. Acesso em: 28 fev. 2018. 
são fomentadas sobre a constituição da "família" como uma construção sócio-histórica e cultural, com o objetivo de subsidiar a análise realizada acerca do "universo católico" que nos é apresentado pelo JOSP.

Dessa forma, procurou-se, mais especificamente, apreender o modo como o campo católico, que nos é apresentado oficialmente pelo JOSP,incorporou o conceito de "família" e o instrumentalizou, apresentando argumentos e discursos que enfatizam a manutenção de uma determinada conduta. $\mathrm{O}$ conceito de campo instrumentalizado para a pesquisa consiste na teorização proposta por Bourdieu (2004):

[...] eu diria que tento elaborar um estruturalismo genético: a análise das estruturas objetivas - as estruturas dos diferentes campos - é inseparável da análise da gênese, nos indivíduos biológicos, das estruturas mentais (que são em parte produto da incorporação das estruturas sociais) e da análise da gênese das próprias estruturas sociais: o espaço social, bem como os grupos que nele se distribuem, são produto de lutas históricas (nas quais os agentes se comprometem em função de sua posição no espaço social e das estruturas mentais através das quais eles apreendem esse espaço) (sic). (Bourdieu, 2004, p. 26).

De acordo com o autor, os campos se apresentam:

à compreensão sincrónica como espaços estruturados de posições (ou de postos) cujas propriedades dependem da sua posição nesses espaços e que podem ser analisadas independentemente das características de seus ocupantes (em parte determinadas por ela). (Bourdieu, 2003, p. 119).

O autor compreende que há tanto propriedades específicas em cada campo quanto propriedades gerais, tais como a presença de lutas e de indivíduos que apresentam certa quantidade de interesses fundamentais em comum, compostos por "tudo o que está ligado à própria existência do campo: daí uma cumplicidade objetiva que está subjacente a todos os antagonismos" (Bourdieu, 2003, p. 121).

Portanto, os conflitos se fazem presentes nos campos, sendo a estrutura destes últimos um "estado da relação de força entre os agentes ou as instituições envolvidas na luta" (Bourdieu, 2003, p. 120), ou ainda da distribuição de capital específico, anteriormente acumulado em outras lutas. Nesse sentido destacam-se as observações de Bonnewitz (2005) de que a sociedade é constituída, para Bourdieu, por um conjunto de campos sociais, mais ou menos autônomos, que são atravessados por lutas entre classes, sendo o mundo social um contexto no qual há um processo de diferenciação progressiva.

Considera-se para a análise, então, o quadro social, no qual se insere o JOSP, e a partir do conceito de família é apresentado como um modelo a ser incorporado, tendo em vista o contexto de conflitos que podem desenvolver-se no que se refere à tentativa de determinação de tal unidade, uma vez que existem diferentes arranjos familiares e que a concepção do que seria uma família apresenta conexões com a subjetividade dos indivíduos, ou seja, com suas concepções pessoais. 
Empreenderam-se, dessa forma, as categorias analíticas a partir das presentes considerações teórico-metodológicas sobre a análise com fontes documentais. Além disso, do diálogo com as elaborações propostas por Karl Mannheim (1981) sobre o pensamento conservador, uma análise das mudanças e aproximações percebidas em ambos os períodos em relação ao modo como tal conceito é apresentado pelo JOSP, buscando elementos referentes à frequência com a qual o assunto é abordado nos dois períodos e os aspectos centrais que foram evidenciados nas matérias publicadas.

\section{Considerações teóricas: a família sob o manto do catolicismo oficial}

É importante ressaltar, de acordo com Decol (1999), que o catolicismo é a vertente religiosa que, no Brasil, possui o mais antigo e tradicional grupo de adeptos, chegando a se confundir com a própria formação histórica da sociedade brasileira. Aldana e Piovezana (2014), versando sobre as falas de Pierucci (1978), destacam que tal religião faz-se presente nos costumes, representações e linguagem dos indivíduos, possuindo uma forte organização que atinge grande parte do território nacional, contando com uma hierarquia extensa e atuante, vinculada inclusive "à cotidianidade familiar e social" (Aldana; Piovezana, 2014, p. 200).

Quando se fala em catolicismo, porém, e se considera a religião como algo ligado ao âmbito social, cultural, entre outros, é preciso questionar as características que tal religião assume em território nacional, portanto, pergunta-se: pode-se falar em um catolicismo no Brasil?

A literatura que trata de tal aspecto é ampla e, de acordo com Souza (2004), refere-se a um assunto complicado, dado o caráter das igrejas católicas como instituições complexas e heterogêneas que possuem divisões e também conflitos internos. Nelas se cruzam diferentes tendências relacionadas às diversidades políticas, sociais, culturais e até mesmo espirituais da sociedade mais ampla em que se insere.

Teixeira (2005), nesse sentido, observa que o catolicismo se revela complexo na realidade sociocultural e histórica brasileira, uma vez que se apresenta como um campo religioso diverso e plural:

Não dá para situar o catolicismo brasileiro num quadro de homogeneidade. $\mathrm{Na}$ verdade, existem muitos "estilos culturais de "ser católico", como vêm mostrando os estudiosos que se debruçam sobre esse fenômeno. São malhas diversificadas de um catolicismo, ou se poderia mesmo falar em catolicismos. Há um catolicismo "santorial", um catolicismo "erudito ou oficial", um catolicismo dos "reafiliados", marcado pela inserção num "regime forte" de intensidade religiosa (CEBs, RCC) e um emergencial catolicismo midiático. Não se trata de realidades estanques e cristalizadas, mas inserem-se num quadro geral marcado por relações de comunicação, de proximidades, tensões e distanciamentos. (Teixeira, 2005, p. 17). 
Teixeira (2005) ainda chama a atenção para o que denomina de capacidade de adaptação e ajustamento dessas formas de catolicismo, que apresentam possibilidades, inclusive, de se diversificar para oferecer, em seu interior, variadas crenças e práticas de fé. Essa capacidade de se adaptar e se ajustar também é um indicativo de que, em diferentes períodos, mesmo se tratando da mesma instituição fisica, seus elementos podem apresentar características diferentes. Compreende-se que um desses casos são as publicações do JOSP, que teria apresentado, em cada período considerado para a pesquisa, publicações com diferentes "focos" em seus conteúdos, o que, porém, não implica que determinados aspectos sejam radicalmente divergentes entre si.

Nesta pesquisa considerou-se, portanto, o universo católico apresentado pelas publicações do JOSP. Porém, quando o catolicismo é citado de forma geral, em relação às suas características e fatores, sejam eles sociais, culturais, econômicos ou históricos, através do arcabouço teórico selecionado para subsidiar a pesquisa, considera-se o caráter multifacetado que essa vertente religiosa apresenta quando se trata de suas configurações no Brasil.

Em relação à temática da pesquisa, é importante ressaltar, de acordo com Esquivel (2003), que o catolicismo oficial tem "vocação" para regulamentar formas de comportamento de diversos segmentos da vida social. Considerando o caráter mutável da vida social, tais como suas diversas nuances e renovações, o que inclui possíveis mudanças de parâmetros e perspectivas sobre comportamentos, trabalho, ética, o catolicismo pode apresentar, de acordo com o autor, sensibilidade às mudanças sociais, porém sem necessariamente desligar-se de seus princípios teológicos, elaborando discursos e práticas de acordo com o ambiente social.

A concepção sobre a composição das famílias ou, ainda, da importância dessa unidade para a religião, seus discursos, práticas e princípios, apresenta-se como um dos elementos que, no caso das publicações do JOSP, não deixou de ser algo relevante para o qual o semanário dedicou-se nos períodos analisados. Para abordar o assunto, porém, é importante que se façam algumas considerações teóricas a respeito da temática referente à família.

Ao se falar das famílias, é de extrema importância considerar que existem diferentes perspectivas em voga, tanto no que diz respeito ao modo como os indivíduos concebem tal categoria, como no que diz respeito às perspectivas e princípios apresentados pelas diferentes culturas e instituições das sociedades. O conceito de "família" traz consigo uma "bagagem cultural" que se traduz em aspectos históricos, sociais, políticos, econômicos, religiosos, e demonstra que as concepções de "família" não são conceitos que encerram significado em si próprios. Estão atrelados à estrutura social, histórica, cultural, econômica e também religiosa mais ampla.

No que se refere à origem das perspectivas sobre a constituição das famílias, da forma pela qual se passou a conceber a ideia de um "molde" específico como um "caminho natural" ou, ainda, um modelo dominante no Brasil, esse processo ocorreu através de conflitos e manipulações e, tal como observa Teruya (2000), essa concepção está ligada a uma tipologia que representa uma cultura dominante que exclui diversos tipos de experiências familiares entre outros grupos sociais. 
Nesse sentido, Sandalowski (2007) chama a atenção para a existência de diversas formas de composições familiares, que possuem caráter plural, porém:

O modelo de família tradicional e, mais tarde, de família nuclear, é tido como forma de organização dominante na sociedade brasileira. Esta situação tem como origem o tradicionalismo, o positivismo e a atuação da Igreja no Brasil ao longo dos anos. (Sandalowski, 2007, p. 1)

Segundo Caes (2006), a concepção de "família” é importante para a Igreja Católica, pois se configurou como um meio para sua inserção na sociedade, assim como a sua concepção de ordem e seus próprios conceitos sobre a formação dos indivíduos. De acordo com o autor:

Em sua atuação, a Igreja procurou responder a todas as questões que se apresentavam como desafios às suas concepções doutrinais e como ameaças à ordem social que considerava legítima. As encíclicas papais, especialmente as publicadas na segunda metade do século XIX, demonstram a preocupação eclesial em debater alguns dos grandes temas do período: Quanta Cura e Syllabus (1864) sobre o liberalismo doutrinal e os chamados "erros modernos"; Quod Apostolici Muneris (1868) sobre o socialismo; Arcanum Divinae Sapientiae (1880) sobre a família; [...] Todas essas manifestações do pensamento católico procuravam evidenciar a imprescindível presença da Igreja e de seus preceitos para o bom andamento das sociedades. [...]

Dentro dessa perspectiva eclesiocêntrica, as práticas pastorais católicas direcionaram-se a combater a secularização e seus partidários, em todos os campos onde o domínio laico se alastrava, acabando por canalizar boa parte de suas atividades para atender à demanda da família e da formação do indivíduo, buscando penetrar, com sua doutrina, o núcleo básico em que se concentravam, naquele momento, as preocupações sociais. (Caes, 2006, p. 1-2).

É relevante destacar, também, as observações de Caes (2006): no século XIX, o debate sobre a constituição da família colocava a Igreja no centro dos interesses da sociedade liberal, o que inclui atenção e ação do Estado para os seus problemas e dificuldades. O autor observa que até mesmo a teoria política pós Revolução Francesa teria se ocupado com definições que abarcavam a concepção de família como uma espécie de instância reguladora. A percepção da composição da família teria, então, chamado a atenção da instituição, uma vez que:

Como "fundamento da sociedade civil", a família se relacionaria com o Estado na condição de reguladora das vontades individuais, submetidas às do chefe da família, e de organizadora dos papéis sociais [...]. A ordem privada da família, fundada no direito paterno, seria a garantia da ordem pública. Por esse status, a família e seus interesses deveriam ser resguardados pelo Estado. (Caes, 2006, p. 2-3).

A instituição teria, então, segundo o autor, voltado sua ação para intervir nesse debate, colocando sua própria concepção de família e os princípios que deveriam regê- 
la, uma vez que a Igreja a concebia como "célula base" da sociedade. Essa preocupação acabou por configurar-se como uma preocupação voltada para a própria regulamentação das relações sociais.

No caso brasileiro e, mais especificamente, na formação discursiva católica, pode-se destacar que, entre os anos de 1930 e 1980, a Igreja teria buscado estabelecer uma relação de interdependência entre o catolicismo, a vida social e a vida familiar, a qual, de acordo com Camargo (1975), desde o início de período colonial foi perpassada por padrões normativos que a instituição católica procurou estabelecer em relação à sua constituição.

Durante os séculos de história do Brasil, observa Camargo (1975), que construíram a formação social do país, a pastoral católica destacou a importância de formular um modelo de família “desejável”. Nessa perspectiva, portanto, o Estado, a Igreja e a Sociedade, apesar das divergências em suas orientações, convergiam para a construção de uma ideologia dominante. ${ }^{11}$

Somam-se a tais observações as elaborações de Wachholz (2011), no sentido de que o catolicismo brasileiro se caracterizou por uma "luta de espíritos" e identidades, como uma demarcação de verdades. Considerando tal característica, podem-se ressaltar as contribuições, embasadas em princípios religiosos, que concorreram para a construção de perspectivas referentes aos "modelos" de família.

O recorte temático, associado à fonte documental católica JOSP, demanda que entendamos os períodos considerados para a análise proposta. A respeito das publicações censuradas, a presente pesquisa dialoga com a elaboração, proposta por Lanza (2006), de três diferentes períodos de publicações do semanário, que possuem relação com a gestão arcebispal da Arquidiocese de São Paulo em cada época: o primeiro (1956 a 1966) envolve a fase final do arcebispado do cardeal Motta, quando ocorreu a fundação do JOSP, e parte do arcebispado do cardeal Agnelo Rossi; o segundo período (1966 a 1970) engloba a transição entre a predominância conservadora e um período progressista na gestão dos arcebispos da Arquidiocese de São Paulo; o terceiro período (1970 a 1985) compreende a ruptura do apoio dado aos governantes militares e o arcebispado de D. Paulo Evaristo Arns. Portanto, as publicações censuradas do semanário compreendem a fase progressista, apesar do JOSP ter manifestado, em edições anteriores ao período, apoio à ação dos governantes militares. ${ }^{12}$

O centro das preocupações apresentadas nas matérias vetadas era, por exemplo, as condições econômicas nas quais as famílias estavam inseridas, o que ocasionava dificuldades, tais como nos relacionamentos:

Eis como o padre Ângelo descreve a situação dos operários: "Os pais de família de nossa área, quase em sua totalidade são imigrantes, sem profissão qualificada, sem preparação, sem orientação básica. O que é lamentável é que

11 De acordo com Camargo (1975), com a Proclamação da República, o Estado secularizou judicialmente os fundamentos ideológicos de sua dominação.

12 As matérias vetadas que se referiam ao tema "família" somam um total de cinco publicações entre as cento e doze matérias vetadas que foram disponibilizadas e digitalizadas. 
não se oferece oportunidade de promoção. O operário trabalha de segunda a sábado, ganha só para comer, sacrifica-se fazendo horas-extra, só vê os filhos dormindo".

E as condições sociais?: "O operário - diz o padre - é um (sic) simples peça, uma máquina dentro da indústria. Nada ali favorece a união dos trabalhadores". [...]

Lazer? "É coisa que praticamente não existe para o povo." - diz o padre.Aos domingos, nem marido nem mulher pode descansar; é preciso construir, reformar, lavar. O único lazer é a televisão, que não promove, mas separa as famílias, impede o diálogo. (JOSP, [197-], lauda 1). ${ }^{13}$

Pode-se observar a presença de um caráter questionador nas publicações dos anos 1970, o que pode ser notado na citação, que expressa, além de críticas às condições precárias nas quais os indivíduos indicados se encontram, preocupações com a falta de tempo e disposição que os indivíduos têm até mesmo para o diálogo em família, indicando a sua sobrecarga de trabalho (além do ambiente de trabalho propriamente dito) e a falta de lazer, que convergem para tal situação. Apresentava críticas sobre a conjuntura social, política e histórica da década de 1970, dando indícios, também, sobre a importância de ações que interferissem nessa realidade:

Padre Angelo (sic) diz que a comunidade paroquial, através de seus membros mais ativos, tem se preocupado com a formação de pequenas comunidades ou grupos onde o pessoal possa se conhecer, se ajudar, refletir sobre os próprios problemas [...]. Nossa preocupação é favorecer a participação e incentivar a colaboração de todos para a solução das dificuldades comuns. Infelizmente - lamenta o padre - é um trabalho muito lento, quando a gravidade da situação exigiria soluções imediatas. (JOSP, [197-], lauda 2). ${ }^{14}$

Ao contrário das matérias vetadas, as publicações do ano de 2015 apresentam caráter que pode ser definido, de acordo com Mannheim (1981), como conservador, visto que enfatizam, em diversos momentos, a necessidade de manutenção de aspectos referentes, por exemplo, à família no chamado "mundo moderno", indicando, em tal processo, problemas que a afligem. Isso pode ser observado em matérias, como, por exemplo: "Ideologia de gênero afeta a família e destrói identidades" que, logo em sua primeira linha, cita uma fala de um professor pedagogo: "A ideologia de gênero não protege a mulher e não protege as minorias. Gênero é para combater a família” (Gomes, 2015, p. 14).

Mannheim (1982), ao dialogar com a Sociologia do Conhecimento, compreende a existência dos chamados estilos de pensamento. Seu entendimento é o de que possuem uma

13 Sobre a autoria desta publicação, não consta o nome do autor, nem a data da publicação. No acervo on-line "Fontes Sobre a Ditadura Militar: Matérias e Documentos Censurados Do Jornal "O São Paulo", a matéria está disponível em: <https://drive.google.com/file/d/0BzFtoWP2meSFQX14d11EWGtBUkE/view>. Acesso em: 4 mar. 2018.

14 Idem à nota de rodapé número 13. Disponível em: < https://drive.google.com/file/d/0BzFtoWP2meSFQX14d11EWGtBUkE/view>. Acesso em: 4 mar. 2018. 
origem social que precisa ser considerada. Os grupos sociais, que também estão inseridos em uma determinada conjuntura e possuem condições, por exemplo, econômicas, culturais ou sociais específicas, aparecem como seus portadores. Portanto, desenvolvimento, estagnação ou mudanças dessas formas de pensamento estão atreladas ao destino e à história desses grupos, que agem dialogando com fatores objetivos relativos à conjuntura.

Os indivíduos, nesse processo, estabelecem diálogos com "padrões de pensamento" (Mannheim, 1981, p. 70) adquiridos de seu meio cultural e dos grupos sociais nos quais se inserem, o que pode se manifestar em seu comportamento, respostas intelectuais e formas de pensamento, podendo apenas reproduzi-los, buscar mudanças e rupturas ou, ainda, adicionar algo de si próprios. Considerando as formas de pensamento no contexto das situações histórico-sociais, Mannheim (1982) concebe que os seres que "pensam" são os indivíduos, inseridos nos grupos, que desenvolvem um estilo de pensamento particular (com suas respostas a diversas situações), com elementos dos indivíduos e de seus grupos.

Portanto, para o autor, há um diálogo entre elementos objetivos e subjetivos. Ao estudar os estilos de pensamento, é importante que se apreendam as formas de manifestação do grupo em questão, considerando fatores conjunturais, como, por exemplo, as posições dos indivíduos na sociedade, buscando as conexões entre o "clima mental" de uma época, os grupos portadores e as formas de pensamento, que se autoinfluenciam e se retroalimentam.

Com base em tais considerações, Mannheim (1981) teoriza duas noções que apresentam características distintas entre si, o conservadorismo e o tradicionalismo. Este último, de acordo com o autor, representa uma inclinação que o indivíduo tem inconscientemente naturalizada em si. O conservadorismo, por sua vez, configura-se como um movimento que expressa tendências sociais e históricas, ou seja, que apresenta conexões com um tempo passado, sendo um tipo de pensamento elaborado de forma consciente e que atua em sentido oposto aos movimentos que buscam mudanças.

Portanto, as (re)formulações do conservadorismo dependem de um conjunto concreto de circunstâncias, que se referem além das "respostas automáticas" do indivíduo. Este é, então, "guiado consciente ou inconscientemente por uma forma de pensamento e ação que tem sua própria história atrás de si” (Mannheim, 1981, p. 103), tendo como uma de suas características o "apego" ao imediato. O conservadorismo apresenta-se, nesse momento, como um movimento significativo em relação às circunstâncias que mudam conforme o contexto no qual está inserido.

[...] o conservadorismo moderno difere do tradicionalismo primordialmente pelo fato de ser uma situação histórica e sociológica particular. O tradicionalismo é uma atitude psicólogica geral que se expressa em diferentes indivíduos como uma tendência a se apegarem ao passado e como temor às inovações. [...] o conservadorismo, por outro lado, é consciente e reflexivo desde o princípio, na medida em que surge como um contra-movimento em oposição consciente ao movimento progressista altamente organizado, coerente e sistemático. (Mannheim, 1981, p. 106-107). 
Mannheim (1981), considerando a conjuntura histórica e as circunstâncias sociais, compreende que o conservadorismo se configura como uma forma de pensamento, em reação aos movimentos que buscam mudanças, formas de pensamento que apresentam traços progressistas.

Ao pensar as publicações atuais do JOSP, pode-se observar um exemplo de tal caráter conservador na já citada entrevista: "Papa Francisco: redefinição do casamento ameaça a família".

Em sua viagem às Filipinas, o Papa falou às famílias reunidas em Manila, pedindo que deem o exemplo e sejam testemunhas proféticas em um mundo que enfrenta ataques à família e à vida:"Toda ameaça à família é uma ameaça à própria sociedade", disse. O Papa afirmou que “a família também é ameaçada pelos esforços crescentes de alguns para redefinir a instituição do casamento, pelo relativismo, pela cultura do efêmero, pela ausência de abertura à vida". (David, 2015b, p. 9,).

Nessa fala, o Papa faz referência a uma estrutura instituída de família para a qual o relativismo e a efemeridade contemporâneos representam ameaças. Esse conceito de família, porém, pode ser observado, em relação ao recorte temporal desta pesquisa, nas publicações do JOSP desde a década de 1970.

Tendo em vista que a pesquisa documental contribui para "dizer muitas coisas sobre a maneira na qual os eventos são construídos, as justificativas empregadas” (May, 2004, p. $205)^{15}$ e considerando o contexto cultural dos períodos analisados, compreende-se que as publicações de ambos os períodos fornecem material para análise e reflexão sobre as divergências e convergências identificadas nos discursos sobre um tema que se faz atual.

Considerando as diferenças em relação às publicações referentes ao tema nos dois recortes temporais e a opção metodológica que implicou a categorização, a primeira categoria analítica consistiu na busca pela concepção de "família" expressa nas publicações do JOSP, considerando os apontamentos de May (2004) de que a análise documental é um método que se processa a partir de semelhanças e diferenças, podendo fornecer leituras particulares por parte dos elaboradores dos documentos, de eventos sociais (May, 2004, p. 205).

Como segunda categoria de análise, procurou-se apreender as diferenças entre os eixos de preocupações quanto às problemáticas relacionadas ao conceito de família que foram veiculadas pelos arcebispos responsáveis pelo JOSP em cada recorte temporal.

Como terceira e última categoria de análise, procurou-se identificar as relações existentes entre o conceito de família apresentado pelo semanário e sua relação com a problemática social, histórica e cultural do contexto social no qual as matérias e edições foram publicadas sob a gestão dos arcebispos responsáveis em cada período.

May (2004) observa que os documentos, além de refletir, também constroem a realidade social e suas versões: "o que as pessoas decidem registrar é informado pelas

15 May (2004) ainda observa que os documentos em uma pesquisa fornecem dados importantes que permitem entender eventos, processos e transformações ocorridos nas próprias relações sociais. 
decisões que, por sua vez, relacionam-se aos ambientes sociais, políticos e econômicos dos quais fazem parte" (p. 213). Nesse sentido, pode-se destacar, novamente, o caráter "não estático" da religião católica no Brasil, que atualmente se vê em um contexto social do qual emergem debates que procuram tanto defender como refutar ou reelaborar a compreensão do conceito de "família". Esse debate, é importante observar, transcende o âmbito religioso, pois além de envolver elementos de ordem pública, como, por exemplo, a política, também envolve a ordem privada, como é o caso das grades de leituras que os indivíduos constroem acerca da realidade.

\section{Divergências e consensos sobre o conceito de família no JOSP}

Em relação ao material selecionado para este trabalho, o fator que primeiramente se destacou foi o número de matérias que abordavam o tema "família" durante os seis anos em que o JOSP sofreu a ação da censura prévia e nas edições de 2015. De um total de 112 matérias vetadas que foram digitalizadas, apenas seis matérias faziam menções à "família", porém, somente cinco desenvolvem a temática, ${ }^{16}$ fazendo alusões às suas condições sociais e econômicas no período em questão.

Em comparação, a proporção de matérias publicadas no ano de 2015 é muito superior, uma vez que o tema foi abordado em 34 diferentes edições (de um total de 52 jornais publicados no referido ano) entre os meses de janeiro e dezembro. ${ }^{17} \mathrm{~A}$ quantidade de publicações apresentadas pelo JOSP que abordaram desde a chamada (pela redação do JOSP) "ideologia de gênero" até os problemas e ameaças às famílias apontam para uma preocupação crescente em relação à atual situação dos arranjos familiares, sua preservação e composição, preocupação que não transparece nas matérias de 1970.

É importante salientar que o jornal JOSP, quando fundado em 1956 pelo Cardeal Carlos Carmelo deVasconcelos Motta, tinha como objetivo, de acordo com Neves Junior (2013), evangelizar a população brasileira e proliferar os princípios da doutrina católica romanizada e ultramontana, que, segundo Gaeta (1997), é um modelo eclesial católico marcado por um caráter que se fecha sobre si mesmo e recusa contato com o mundo chamado moderno, imposto pelo Vaticano nos fins do século XIX. ${ }^{18}$ Com base nesses fatores, torna-se possível inferir o caráter conservador que pode ser atribuído aos objetivos das publicações do JOSP em um primeiro momento, no qual houve, temporariamente,

16 A sexta matéria não se dedica a desenvolver o tema, apenas cita o termo "família" uma vez, fazendo referência a uma fala encenada em uma apresentação teatral em comemoração à data de $1^{\circ}$ de maio. Disponível em: <https://drive.google.com/file/d/0BzFtoWP2meSFUGNCNWxTRlFmSzQ/ view>. Acesso em: 26 fev. 2018.

17 A seleção e a leitura das edições ocorreram com base em um critério que consistiu em conter a palavra "família" nos títulos de suas matérias componentes.

18 Para maiores informações, acessar "A Cultura clerical e a folia popular" (Gaeta, 1997). Disponível em: <http://www.scielo.br/scielo.php?pid=S0102-01881997000200010\&script=sci_ arttext\&tlng=es>.Acesso em: 4 mar. 2018. 
"concordância do alto clero paulistano com a ação golpista de 1964, porque ela era tida como responsável pela reinstalação da ordem ameaçada pelo avanço bolchevista no Brasil" (Lanza, 2006, p. 140).

De acordo com Lanza (2006), porém, a partir do ano 1966 tem início um processo de transição desse caráter conservador das publicações, que culminou na ruptura definitiva do apoio aos ditadores militares (1970 a 1985). Nessa conjuntura, as publicações adquiriram um caráter que questionava e apresentava críticas aos elementos percebidos como prejudiciais aos indivíduos e aos direitos humanos, tendo a família sido apresentada como uma das vítimas das políticas do Estado contra trabalhadores, movimentos sociais, militantes, dentre outros, além das mazelas sociais e econômicas, por isso as publicações são consideradas progressistas no dado momento histórico e político-social. Contudo, o limite da posição progressista esbarra na concepção de família nuclear.

Considerando tais fatores, a análise documental procurou apreender a concepção de família apresentada nas publicações vetadas, assim como os princípios vinculados à família. Com a leitura e a análise, no entanto, constatou-se que as matérias não falam diretamente de sua composição, mas fornecem indícios de um modelo que se encaixa nos moldes da nomeada "família" tradicional (pai e mãe e/ou filhos), não questionando ou fazendo menção, portanto, à diversidade de configurações familiares:

Missão da Família - “Aqui encontramos - continuam eles - a missão cristã
da vida conjugal e familiar. No meio de um mundo dividido e opressor, são
os cristãos chamados a patentear a força libertadora do amor de Jesus. Pelo
sacramento do matrimônio, os cônjuges dão-se mutuamente com fidelidade
perpétua, da mesma forma como cristo amou a Igreja até o fim e por ela se
entregou. É esse amor de doação que está na origem da vida e educação dos
filhos e na intimidade da comunhão familiar. (JOSP, 1977, lauda 2). ${ }^{19}$

Pode-se perceber nessa publicação referências à "família cristã" que envolvem os cônjuges e os filhos, além de "valores morais" referentes ao matrimônio e à fidelidade. Destacou-se também o questionamento implícito ao direito de divórcio, sendo outra questão favorecedora da perspectiva de que, apesar de ser uma publicação do período considerado progressista, ${ }^{20}$ ainda sim apresenta um conceito que conserva essa noção de família, pois evidencia uma forma de resistência ao que poderia romper com essa unidade familiar nuclear.

19 Disponível em: <https://drive.google.com/file/d/0BzFtoWP2meSFUXRLbWxGN2xPRGM/ view>.Acesso em: 26 fev. 2018.

20 Outra fala que ilustra esse caráter progressista no dado momento histórico encontra-se na matéria vetada "A Igreja Católica e a Segurança Nacional”, de autoria de Oglai (somente consta seu primeiro nome na matéria): "Falando sobre a atuação da Igreja Católica no que diz respeito aos direitos humanos, diz a Pro Vita Mundi, que a igreja não aceitando mais se recolher à sacristia, partiu para o campo social e político. Dá surgirem conflitos com autoridades governamentais e militares [...]. A Igreja Católica se sente obrigada, por razões teológicas e pastorais, a não aceitar a ideologia da segurança nacional.” (Oglai, 1978, lauda 1). Disponível em: <https://drive.google. com/file/d/0BzFtoWP2meSFY0t2TmJWWG5Gc0k/view>. Acesso em: 26 fev. 2018. 
Nota-se que, nas publicações vetadas, o centro de preocupações apresentado é a situação econômica na qual as famílias e trabalhadores estão inseridos. Dos seis documentos vetados, quatro fazem referências a tal fator, sendo todos os arquivos voltados para assuntos ligados à desigualdade econômica, por exemplo, no caso dos trabalhadores e do movimento operário. Tal constatação pode ser observada nesta publicação do ano de 1976:

Eram pouco mais de duas horas da tarde e várias pessoas, homens e mulheres, moços e velhos, família inteiras com crianças no colo, já estavam na porta da casa do Tabor $[\ldots]$.

Falando sobre o progresso do Brasil durante os últimos treze anos sobre o chamado "milagre brasileiros" (sic), o orador afirmou ter sido ele conseguido encima (sic) do dinheiro tirado dos salários e colocado nas grandes indústrias, graças ao arrocho salarial que foi imposto sobre todas as classes trabalhadoras e que, durante os últimos anos, aumentaram sua produtividade, aguentaram a inflação, a alta do custo de vida para o desfrute de poucos, de muitos poucos. E de uma coisa pode se ter certeza, prosseguiu, estão falando por aí que “o Brasil é feito por nós", e realmente é mesmo, mas suas riquezas não são divididas entre nós. (JOSP, 1976, laudas 1 e 3). ${ }^{21}$

Pode-se observar, portanto, que o foco principal da preocupação em relação às famílias, apesar de referências às condições ("mundo dividido", falta de comunicação entre marido, mulher e filhos), centra-se na situação econômica dos indivíduos.

Outro bispo, Dom Luciano Pedro Mendes de Almeida, disse, durante o lançamento do abaixo assinado em São Matheus, no dia 2 de outubro de 1977, “que estamos convencidos de que um dos problemas que mais aflige a família hoje é este, a alta do custo de vida, de pessoas que não conseguem se alimentar direito, dos que não tem (sic) o que comer por causa do pequeno e injusto salário que recebem" (sic). (JOSP, 1978, lauda 1). ${ }^{22}$

Com base nas matérias até agora expostas, percebe-se que o eixo das preocupações em relação aos problemas das famílias estava voltado para fatores "externos” à sua composição, ou seja, o problema central não é a formação do núcleo familiar, apesar de essa problemática ainda permear o cerne de debate instituído pelo semanário durante esse período, mas sua situação em relação a fatores econômicos localizados na estrutura produtiva e econômica mais ampla da sociedade e também a fatores decorrentes dessa situação.

O importante é abrir o olhar, perceber a situação: quando a gente anda pelas ruas ve (sic) o povo andando emagrecido [...] porque não tem o alimento suficiente. Devemos assumir esse compromisso agora. O que nós podemos

21 No acervo, está disponível apenas a informação acerca do ano de publicação da matéria. Disponível em: <https://drive.google.com/file/d/0BzFtoWP2meSFa0hqLV9QdWJ1RW8/ view?pref=2\&pli=1>. Acesso em: 4 mar. 2018.

22 No que tange ao autor da matéria, consta apenas seu primeiro nome, que é Tarcisio. Disponível em: $<$ https://drive.google.com/file/d/0BzFtoWP2meSFMUxqanp6V1RDRjQ/view>. Acesso em: 4 mar. 2018. 
é pouco. Mas é o que nós podemos e devemos para (sic), no próximo passo, podermos ser uma sementinha, um pequeno fermento na transformação social (sic). (JOSP, 1978, lauda 2). ${ }^{23}$

Considerando essa preocupação com relação, por exemplo, à situação econômica e social na qual a população se encontrava, é importante ressaltar as divisões internas da própria Igreja de São Paulo, uma vez que, historicamente falando, a partir do Concílio Vaticano II (1961-1965) e das conferências Episcopais de Medellín (1968) e Puebla (1979), mudou-se o "foco" de parte do clero da Igreja Católica Latino-Americana. As atenções voltaram-se para as massas populares. Wanderley (2007) observa que tal fato ocasionou divergências no clero católico brasileiro ${ }^{24}$ entre:

[..] conservadores liderados pelos bispos da TFP (Tradição Família e Propriedade) - que se posicionaram como partidários da 17 Doutrina que tinha como intuito restaurar os dogmas católicos romanizados centralizando o poder na sede do Vaticano - e progressistas, representados pelo grupo de Dom Hélder Câmara - que apoiaram as camadas populares e combateram os abusos militares durante a ditadura, assim como lutaram pela redemocratização do país. (Wanderley, 2007, p. 26-27).

Portanto, esse grupo progressista teria atuado de forma convergente ao processo de redemocratização do país e entre eles estava o então Arcebispo da Arquidiocese da cidade de São Paulo, Dom Paulo E. Arns, que, no período em que as matérias foram vetadas, também era responsável pelo JOSP. Na conjuntura da censura às publicações, pode-se perceber, portanto, um diálogo de indivíduos desse grupo progressista com a situação político-social do período no sentido de questioná-la e demandar mudanças, porém, fazendo manutenção de um discurso que busca zelar e preservar a constituição da família nuclear, sendo esse um indicativo de uma perspectiva conservadora.

Nas publicações do ano de 2015, pode-se apreender a presença frequente das referências à construção e preservação das famílias na contemporaneidade, além de menções mais diretas sobre sua constituição, que são explicitamente apresentadas ao leitor junto com apontamentos sobre fatores que prejudicam esses processos. Entre os 31 jornais, foram selecionadas matérias de 10 edições, de forma intencional, como expressão desse conjunto, e essas serão apresentadas e cotejadas no desenvolvimento do texto a seguir.

De uma forma geral, pode-se perceber não só pela proporção na qual o tema é abordado, mas, além disso, pelas próprias publicações, que a família ganha destaque e importância como uma unidade a ser preservada pelo bem da sociedade, o que pode ser exemplificado pela manchete da edição correspondente ao período de 1 a 7 de julho:

23 Disponível em: <https://drive.google.com/file/d/0BzFtoWP2meSFMUxqanp6V1RDRjQ/ view $>$. Acesso em: 4 mar. 2018.

24 Löwy (2000) destaca, por exemplo, que na década de 1960 teria surgido uma nova tendência, a "Esquerda Católica", que atuava em sentido contrário aos princípios do capitalismo, em prol de uma estrutura social mais justa e mais humana. 
"Pilar da sociedade, família tem na Igreja apoio à missão do mundo contemporâneo" (Gomes, 2015, p. 1).

Pode-se apreender, também, uma busca em associar a proteção dessa unidade aos princípios religiosos da instituição, o que pode ser observado na fala: "A família e a Igreja são mutuamente dependentes, de modo que, se a família vai mal, a Igreja também vai mal (Monteiro, 2015, p. 21). A família é chamada, inclusive, de Igreja Doméstica, sendo definida, em fala feita pelo Papa, como uma pequena Igreja (Roberto; Geronazzo, 2015, p. 4).

Pode-se inferir, a partir da abordagem discursiva sobre a importância e a preservação da família por parte da Igreja, a existência de uma busca por um meio de interferir na realidade social e orientar elementos da vida privada dos indivíduos, visto que a "proteção" da unidade familiar é associada diretamente com o "bem-estar" da Igreja e vice-versa. ${ }^{25}$ Pode-se perceber esse fator, também, em matérias que evidenciam indivíduos presentes na realidade social, como o casal homoafetivo Stefano Gabbana e Domenico Dolce em entrevista à revista italiana "Panorama", discursando em favor não só da manutenção da noção de família nuclear, como também destacando elementos que podem vir a prejudicá-la:

Dolce afirmou que procriar deve ser um ato de amor, não um processo artificial: "Nós, um casal gay, dizemos não à adoção gay. Chega de crianças [produzidas] quimicamente e de úteros de aluguel. As crianças deveriam ter uma mãe e um pai”.

Não é a primeira vez que a dupla se manifesta a favor da família. Em uma entrevista em 2013, Dolce havia declarado claramente: "Eu não acredito em casamento gay". Para Dolce e Gabbana a família tradicional não é apenas uma moda, mas "uma das coisas que não podem ser modificadas". (David, 2015a, p. 9).

Tais afirmações são significativas quando se considera que há diversas demandas, na atualidade, pelo reconhecimento das diversidades, o que inclui as várias organizações familiares. Então, o jornal, que é o meio de comunicação oficial da maior Arquidiocese Católica do Brasil, apresenta, em suas reportagens, concepções que convergem, por exemplo, para a preservação da ideia da composição pai, mãe e filhos como modelo de família, para o não reconhecimento dos casamentos homoafetivos e do processo de

25 Na edição correspondente aos dias 6 a 12 de maio, o Padre Denilson Geraldo faz considerações que reforçam essa perspectiva. Reafirma a família como um "bem público", considerando elementos que abrangem a escolaridade das crianças, trabalho dos pais, âmbito econômico, emocional e religioso, entre outros: "O bem-estar da pessoa passa pela família e, sem essa natural instituição humana, nenhuma sociedade se sustenta, porque a família é a primeira, fundamental e natural experiência de sociabilidade”. (Geraldo, 2015, p. 2). 
adoção por parte desses casais, o que pode ser observado em diversas edições ${ }^{26}$ do JOSP, incluindo as que falam sobre o conteúdo dos textos apresentados no Sínodo:

Sobre as uniões gays, o documento enfatiza: "Não há base alguma para assimilar ou estabelecer analogias, mesmo remotas, entre uniões homossexuais e o plano de Deus para o casamento e a família”. (Geronazzo, 2015, p. 12).

Em leitura às edições atuais, pode-se perceber que essas expressam, portanto, uma concepção que está alinhada a uma noção de família nuclear católica, porém vai além da ideia de composição familiar, pois apresentam discursos que abordam temas sobre os quais essas matérias buscam alguma forma de ação e interferência, como é o caso da legalização e prática do aborto, ${ }^{27}$ casamentos homoafetivos, discussões sobre gênero, ${ }^{28}$ educação dos filhos, ${ }^{29}$ entre outros fatores.

Os resultados do Relatório do Sínodo de 2015, por sua vez, foram esclarecedores no sentido de apreender qual é o núcleo familiar apresentado pelas publicações. Ele pode ser apreendido em um trecho de reportagem que contém uma fala do atual arcebispo de São Paulo, D. Odilo Scherer: "a família, baseada no matrimônio de um homem e de uma mulher, é o local magnífico e insubstituível do amor pessoal que transmite a vida" (David, 2015c, p. 22).

Nessa mesma matéria sobre os resultados do Sínodo, demonstra-se preocupação em relação ao núcleo familiar apresentado, que se estende por diversos fatores. Abrange desde a chamada "Ideologia de Gênero" - que seria um desafio por negar "a diferença e a complementariedade natural entre o homem e a mulher" (David, 2015c, p. 22) - até o crescimento de uma mentalidade contraceptiva e abortista, além de outros "problemas" citados nas outras edições ao longo do ano de 2015 , como a rejeição à prática do aborto ou a individualidade crescente dos indivíduos na contemporaneidade.

A cultura contemporânea questiona e, de alguma forma, corrói as certezas a respeito das convicções mais elementares sobre o casamento e a família. Já não mais aparece claramente qual seja a razão de ser da família e se buscam soluções alternativas ao casamento tradicional entre um homem e uma mulher $[\ldots]$.

As "verdades" sobre o ser humano, o casamento, a família e as relações

26 A questão do casamento homoafetivo foi abordada em oito das 34 edições, ao passo que a adoção (por esses casais) foi abordada em duas. Ambas as temáticas trouxeram, de forma geral, falas contrárias à adoção e sobre a impossibilidade de se equiparar, na instituição religiosa, o casamento homoafetivo ao casamento heteroafetivo.

27 A temática do aborto foi abordada em nove das 34 edições, trazendo, entre outros temas, notícias sobre posicionamentos contrários à sua legalização e prática.

28 Referências sobre o que se nomeou como "ideologia de gênero" apareceram em 14 das 34 edições, sendo frequente a afirmação de que o gênero desconstrói a noção da família.

29 Essa temática também apareceu em algumas edições que se referiam ao ensino de gênero na escola, que ressaltaram a importância da família ser a responsável por ensinar valores morais e educar os filhos anteriormente à escola e, posteriormente, em conjunto com ela. 
humanas básicas tornaram-se líquidas e se estão vaporizando cada vez mais. (Scherer, 2015a, p. 3).

Considerando tais falas, percebe-se que, apesar de apontarem muitas vezes para fatores externos ao núcleo familiar, como a influência da Ideologia de Gênero, ou para tendências contemporâneas que poderiam influenciar e prejudicar a família, ${ }^{30} \mathrm{o}$ centro de preocupações é "interno" à estrutura de família e refere-se à possibilidade de que essa tradicional formação e seus princípios (apresentados pelo JOSP) percam paulatinamente o sentido para os indivíduos, fator que pode ser apreendido em leitura de matérias como a que se segue.

Fala-se com frequência sobre a crise da família e ela é real, mas é preciso entender as principais causas e considerar que a família cristã como tal não entrou em crise, mas só a família moderna, pois reflete o individualismo moderno. (Fernandes, 2015, p. 14).

Nesse sentido, é importante ter em vista as observações de Esquivel (2003), apresentadas anteriormente, sobre a religião católica ser uma instituição que atua no sentido de agir sobre a consciência dos indivíduos e que pretende orientar e regular os princípios organizadores da sociedade. Segundo Busin (2011), a experiência religiosa modela subjetividades, conduzindo a diferentes formas de perceber e estar na realidade e de viver relações sociais.

Tal posicionamento pode ser considerado uma reação conservadora, a qual, de acordo com os apontamentos de Wanderley (2003), corresponderia à defesa da manutenção de uma ordem, da disciplina, do tradicional. Um dos fatores presentes na realidade brasileira que pode ter relação com as mudanças contra as quais tais publicações representam uma reação, poderiam ser os emergentes debates sobre a convivência com as diversidades, sobre a composição das famílias, casamento homoafetivo, gênero, entre outros, que vêm ganhando cada vez mais espaço no cotidiano.

As convergências entre as publicações nos dois períodos analisados, em geral, fazem alusão à estrutura familiar apresentada (pai, mãe e/ou filhos), aos problemas em relação ao âmbito econômico e à comunicação entre os membros das famílias, além de fazer referências, por exemplo, ao divórcio. Essa postura adversa manteve-se nos dois períodos, porém, nas publicações de 2015, podem-se notar falas sobre o acolhimento e o lugar dos casais de segunda união na igreja católica.

O que o sínodo falou com clareza é que esses casais não estão excomungados, nem devem se considerar como tais; são filhos da Igreja e têm muitas possibilidades de se sentirem parte da Igreja e em comunhão com Deus. (Scherer, 2015b, p. 21).

30 Referências a esses problemas foram identificadas em 16 das 34 edições. Entre outros elementos, foram citados com frequência: miséria, pobreza, divórcio, trabalho excessivo, dificuldades financeiras, comunicação, mudanças culturais, entre outros. 
Por fim, observa-se que há tanto diferenças quanto similaridades entre as publicações dos dois períodos analisados. Apesar de seu caráter progressista, as publicações da década de 1970 e as de 2015 apresentaram, considerando a diversidade de temas abordados, a mesma estrutura de família, o que evidencia um caráter conservador em relação à perspectiva de "defesa” da estrutura de família apresentada pelo JOSP.

\section{Considerações finais}

Os resultados desta pesquisa, com base nos documentos vetados do JOSP e nas atuais edições, apontam que, apesar das divergências sócio-históricas e políticas entre os diferentes períodos analisados, o JOSP apresentou a mesma perspectiva em relação à composição da chamada "família tradicional". Foram constatadas, porém, diferenças entre os temas abordados e os discursos veiculados nas matérias, pois, no ano de 2015, além da disparidade no número de matérias que falaram sobre a família brasileira, houve também uma diversificação dos temas abordados: temas relacionados às relações de gênero, educação escolar, entre outros.

$\mathrm{Na}$ análise das matérias vetadas, destaca-se que o discurso sobre família está inserido em um determinado contexto sócio-histórico e político, que se caracterizou pela predominância de abordagens temáticas referentes ao trabalho, baixos salários, por exemplo, apresentando como projeto de defesa diretamente relacionado ao núcleo familiar a "bandeira" contra alguns temas: aborto e divórcio.

Nas matérias do ano de 2015, observou-se que o semanário apresentou um projeto político da sede católica em questão - a Arquidiocese de São Paulo. Pode-se inferir que ele configura uma forma de contraposição política aos debates a respeito da comunidade LGBT (lésbicas, gays, bissexuais, travestis e transexuais) e outras formações familiares que destoem da estrutura nuclear apresentada pelo semanário.

Essa forma de inserir-se no debate sobre a composição das famílias, dado o fato de que existem diversas formações que dialogam com as concepções pessoais dos próprios indivíduos em sua vida pessoal, destaca o caráter pró-conservador das publicações do ano de 2015. Até mesmo antidemocrático, uma vez que procura instrumentalizar uma fórmula fixa de família, ligada a uma concepção que traz consigo uma "bagagem histórica", e influi publicamente no aspecto que diz respeito à vida privada dos indivíduos. Isso se agrava quando se considera, por exemplo, o caso do Estatuto da Família, pois tal concepção, relacionada a princípios religiosos, pode interferir legalmente nos direitos e leis que abrangem as famílias.

$\mathrm{Na}$ atual conjuntura internacional e brasileira, grupos conservadores produzem agendas que expressam processos de intolerância, violência e desrespeito às diferenças individuais ou familiares. Tanto na mídia de massa como nos meios alternativos de comunicação, inúmeros casos e reportagens indicam o acirramento de grupos conservadores e atos violentos contra a população LGBT (lésbicas, gays, bissexuais, travestis e transexuais). Por isso, é relevante à sociedade atual ampliar o conhecimento e desconstruir discursos como 
os que foram valorizados nas edições do JOSP, haja visto a supervalorização das famílias nos moldes tradicionais e suas consequências de (des)reconhecimento ${ }^{31}$ das diferentes identidades e formas de constituição familiar.

Por fim, cabe observar que esta pesquisa suscitou outros temas e estes poderão ser desenvolvidos a partir das matérias inéditas censuradas, entre eles, as possíveis ligações da gestão arcebispal com as publicações dos diferentes períodos do semanário.

\section{Referências}

ALBERTO, Rafael. Sínodo em Outubro:Vocação e Missão da Família. O São Paulo, ano 60, n. 3054,3 a 9 de junho de 2015 .

ALDANA, M.; PIOVEZANA, Leonel. Direitos Sexuais e Reprodutivos e Laicidade do Estado. Numen: revista de estudos e pesquisa da religião, Juiz de Fora, Minas Gerais, v. 17, n. 1, p. 190-203, 2014.

AQUINO, Gustavo Ramus. Anarquismos, Cristianismo e Literatura Social no Brasil (1890-1938). 2011.215 f. Dissertação (Mestrado Acadêmico em Ciências Sociais) - Pontifícia Universidade Católica de São Paulo, São Paulo, 2011.

BONNEWITZ, Patrice. Primeiras lições sobre a sociologia de Pierre Bourdieu. Petrópolis, RJ:Vozes, 2005.

BOURDIEU, Pierre. Coisas ditas. São Paulo: Brasiliense, 2004.

Questões de Sociologia. Tradução de Miguel Serras Pereira. Lisboa: Fim de Século - Edições, Sociedade Unipessoal, Ltda., 2003. p. 119-127.

BUSIN,Valéria Melki. Religião, Sexualidades e Gênero. Rever: Revista de Estudos da Religião, ano 11, n. 1, jan./ jun. 2011.

CAES, André Luiz. A Família e a Reestruturação da Igreja:Alguns Aspectos da Doutrina Católica Sobre a Família (1890-1934). In: SIMPÓSIO DA ABHR, 2006, São Luís. Anais... São Luís: Universidade Federal do Maranhão, 2006. Disponível em: <http://www.abhr.org.br/publicacoes/anais-dos-simposios/anais-do-viii-simposio-daabhr-ufma-sao-luis-2007>. Acesso em: 4 mar. 2018.

CAMARGO, Cândido Procópio Ferreira de. Catolicismo e família no Brasil contemporâneo. Estudos CEBRAP, São Paulo, v. 12, p. 1149-60, abr./jun. 1975.

CELLARD,André.A análise documental. In:POUPART, Jean et al. A pesquisa qualitativa: enfoques epistemológicos e metodológicos. Petrópolis, RJ:Vozes, 2008. p. 295-316.

DAVID, Filipe. Dolce e Gabbana em defesa da família. O São Paulo, ano 60, n. 3043, 18 a 24 de março de 2015 a. (Fonte: CNA).

. Papa Francisco: Redefinição do Casamento Ameaça a Família. O São Paulo, ano 59, n. 3035, 21 a 27 de janeiro de 2015b. (Fonte: CNA).

. Relatório Final do Sínodo - Parte I. Primeira parte do relatório apresenta situação da família no mundo de hoje. O São Paulo, ano 60, n. 3075, 28 de outubro a 03 de novembro de 2015c.

DECOL, Rene. Mudança Religiosa no Brasil: uma visão demográfica. Revista Brasileira de Estudos de População, Belo Horizonte, v. 16, n. 1/2, p. 121-137, jan./dez. 1999.

ESQUIVEL, Juan Cruz. Igreja Católica e Estado na Argentina e no Brasil. Notas Introdutórias Para Uma Análise Comparativa. Ciências Sociais e Religião, Porto Alegre, ano 5, n. 5, p. 191-223, out. 2003.

FERNANDES, Nayá. Um modo de ver a família. O São Paulo, ano 60, n. 3045, 01 a 07 de abril de 2015.

31 Ação de tentar fazer retroceder as conquistas dos direitos civis da população LGBT e das diferentes formas de constituição familiar. 
FONSECA JÚNIOR, Wilson Corrêa da. Análise de Conteúdo. In: DUARTE, Jorge; BARROS, Antonio (Org.). Métodos e técnicas de pesquisa em comunicação. 2. ed. São Paulo: Atlas, 2009. p. 280-303.

GAETA, Maria Aparecida Junqueira Veiga. A Cultura clerical e a folia popular. Revista Brasileira de História, São Paulo, v. 17, n. 34, p. 183-202, 1997. Disponível em: <http://www.scielo.br/scielo.php?pid=S010201881997000200010\&script=sci_arttext\&tlng=es $>$. Acesso em: 3 jan. 2015.

GERALDO, Padre Denilson. O desejo de família semeado pelo Criador. O São Paulo, ano 60, n. 3050,6 a 12 de maio de 2015.

GERONAZZO, Fernando. Instrumento de Trabalho do Sínodo Reflete sobre Desafios, Vocação e Missão da Família. O São Paulo, ano 60, n. 3058, p. 12, 1 a 7 de julho de 2015.

GOMES, Daniel. Manter as famílias plenamente vivas é a missão. O São Paulo, ano 60, n. 3058,1 a 7 de julho de 2015.

IBGE - Instituto Brasileiro de Geografia e Estatística. Censo 2010: número de católicos cai e aumenta o de evangélicos, espíritas e sem religião. Brasília, 29/6/2012. Disponível em: <https://censo2010.ibge.gov.br/noticiascenso id $=3 \&$ idnoticia $=2170 \& v i e w=$ noticia $>$. Acesso em: 4 mar. 2018.

KONINGS, Johan. XII Assembleia Geral Ordinária do Sínodo dos Bispos sobre a Palavra de Deus. Perspectiva Teológica, Belo Horizonte, v. 41, n. 114, p. 165-190, 2009. Disponível em: <http://faje.edu.br/periodicos2/index.

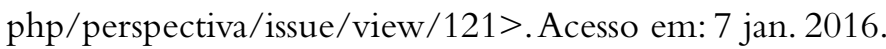

LANZA, Fabio. Matrizes Ideológicas dos Arcebispos Paulistanos (1956-1985): um olhar sob o prisma do semanário O São Paulo. 2006. 253 f. Tese (Doutorado em Ciências Sociais) - Pontificia Universidade Católica de São Paulo, São Paulo, 2006.

LÖWY, Michael. A guerra dos deuses: religião e política na América Latina. Petrópolis, RJ:Vozes, 2000.

MADURO, Otto. Religião e luta de classes. Petrópolis, RJ:Vozes, 1981.

MANNHEIM, Karl. Abordagem Preliminar do Problema. In: MANNHEIM, Karl. Ideologia e Utopia. Rio de Janeiro: Zahar Editores, 1982. p. 29-60.

O pensamento conservador. In: MARTINS, José de Souza (Org.). Introdução crítica à sociologia rural. São Paulo: Hucitec, 1981.

MAY,Tim. Pesquisa Social: questões, métodos e processos. 3. ed. Porto Alegre: Artmed, 2004.

MONTEIRO, Diego. Família e Igreja são Mutuamente Dependentes. O São Paulo, ano 60, n. 3065,19 a 25 de agosto de 2015 .

NERI, Marcelo Cortês (Coord.). Novo Mapa Das Religiões. Rio de Janeiro: FGV: CPS, 2011. Disponível em: <http://www.cps.fgv.br/cps/bd/rel3/REN_texto_FGV_CPS_Neri.pdf>.Acesso em: 4 mar. 2018.

NEVES JUNIOR, José Wilson Assis. Os bastidores da ditadura militar no Brasil (1964-85): Dos documentos do DEOPS às matérias vetadas do semanário O São Paulo. 2013. 49 f. Trabalho de Conclusão de Curso em Ciências Sociais - Universidade Estadual de Londrina, Londrina, Paraná, 2013.

PIERUCCI, Antônio Flávio de Oliveira. Igreja: Contradições e Acomodações. Ideologia do Clero Católico no Brasil. Cadernos CEBRAP, n. 30, São Paulo: Editora Brasiliense, 1978.

PRANDI, José Reginaldo. Catolicismo e Família: transformações de uma ideologia. Cadernos do Cebrap, São Paulo, n. 21, p. 1-70, 1975.

ROBERTO, Michelino; GERONAZZO, Fernando. Igreja Doméstica. O São Paulo, ano 60, n. 3059 , p. 4, 8 a 14 de julho de 2015.

SANDALOWSKI, Mari Cleise. As famílias no contexto social brasileiro. Revista do Centro de Ciências Sociais e Humanas, Universidade Federal de Santa Maria, Santa Maria, Rio Grande do Sul, v. 20, p. 61-67, 2007.

SCHERER, Cardeal Odilo Pedro. Família: O amor é a Nossa Vocação. O São Paulo, ano 60, n. 3070,23 a 29 de setembro de 2015a. 
Sínodo: uma nova tomada de consciência em relação à família. O São Paulo, ano 60, n. 3075, 28 de outubro a 03 de novembro de 2015 b.

SOUZA, Luiz Alberto Gómez de. As várias faces da igreja católica. Estudos Avançados, São Paulo, v. 18, n. 52, p. 77-95, set./dez. 2004. Disponível em: <https://goo.gl/E4yVCf>. Acesso em: 17 dez. 2015.

TEIXEIRA, Faustino. Faces do catolicismo brasileiro contemporâneo. Revista USP, São Paulo, n. 67, p. 14-23, set./nov. 2005.

TERUYA, Marisa Tayra. A Família na Historiografia Brasileira: bases e perspectivas teóricas. In: ENCONTRO NACIONAL DE ESTUDOS POPULACIONAIS, 12., p. 23-27, out. 2000, Caxambú, Minas Gerais. Anais... Caxambú, MG: ABEP, 2000. Disponível em: <http://www.abep.org.br/publicacoes/index.php/anais/article/ view/1041>. Acesso em: 4 mar. 2018.

WACHHOLZ, Wilhelm. Identidades religiosas brasileiras e seus exclusivismos. Horizonte, Belo Horizonte, v. 9, n. 23, p. 782-798, out./dez. 2011.

WANDERLEY, Luiz Eduardo W. Democracia e Igreja Popular. São Paulo: EDUC, 2007.

WANDERLEY, Luiz Eduardo W. Desafios da Igreja Católica e política no Brasil. In: INSTITUTO NACIONAL DE PASTORAL (Org.). Presença pública da Igreja no Brasil (1952-2002). São Paulo: Paulinas, 2003. p. 459-479.

\section{FONTES DOCUMENTAIS DO SEMANÁRIO O SÃO PAULO}

\section{Publicações Censuradas (1972-1978) ${ }^{32}$}

JOSP - Jornal O São Paulo. [197-], Lauda 1. Disponível em: <https://drive.google.com/file/ d/0BzFtoWP2meSFQX14d11EWGtBUkE/view>. Acesso em: 4 mar. 2018.

. [1976], Laudas 1 e 3. Disponível em: <https://drive.google.com/file/d/0BzFtoWP2meSFa0hqLV9QdWJ1RW8/view?pref=2\&pli=1>. Acesso em: 4 mar. 2018.

Liberdade Sindical: Direito Fundamental. Renato de Almeida, 1977, Lauda 2. Disponível em: < https:// drive.google.com/file/d/0BzFtoWP2meSFUXRLbWxGN2xPRGM/view>. Acesso em: 4 mar. 2018.

A Igreja Católica e a Segurança Nacional. Oglai, 1978, Lauda 1. Disponível em: <https://drive.google.com/ file/d/0BzFtoWP2meSFY0t2TmJWWG5Gc0k/view>. Acesso em: 26 fev. 2018.

Custo de Vida. Tarcisio, 1978, Lauda 1. Disponível em: <https://drive.google.com/file/d/0BzFtoWP2meSFMUxqanp6V1RDRjQ/view>.Acesso em: 4 mar. 2018.

Custo de Vida. Tarcisio, 1978, Lauda 2. Disponível em: < https://drive.google.com/file/d/0BzFtoWP2meSFUGNCNWxTRlFmSzQ/view>. Acesso em: 4 mar. 2018.

. $1^{\circ}$ de Maio.Tarcisio, 1978. Disponível em: <https://drive.google.com/file/d/0BzFtoWP2meSFUGNCNWxTR1FmSzQ/view>. Acesso em: 4 mar. 2018.

32 Quando foi realizada a catalogação on-line do arquivo das matérias censuradas, não constavam, em alguns arquivos, informações como sua autoria, o ano de publicação e o título. Dessa forma, para a organização das referências das fontes mobilizadas para a presente análise, foram listadas as informações disponíveis. 


\title{
Divergences and convergences about the concept offamily in the newspaper "O São Paulo"
}

\begin{abstract}
The current national debates about the concept of family has given rise to this article, which highlights the Catholic field, specifically based on the Catholic weekly newspaper O São Paulo - JOSP, official organ of the Archdiocese of São Paulo,the largest one in Brazil. The research identified the convergences and divergences regarding the ideological positions on the concept of "family" based on the understanding and the interpretation of JOSP publications. The documentary source was analyzed from two different temporal cuts, that of the articles vetoed by the previous censorship of the military dictatorship in the 1970s and that of the publications in 2015, when the subject became an issue on the national agenda. Differences were identified between the themes and the discourses of the articles with regard to gender relations, homoaffective marriage and adoption, among others. However, we identify the same perspective in regard to the advocacy of what is named as the "traditional family".
\end{abstract}

Key words: Sociology of Religions, family, Military Dictatorship (1964-1985), O São Paulo newspaper.

\section{Convergencias y diferencias en el concepto de "familia" en el semanario católico "O São Paulo"}

\section{Resumen}

Los debates nacionales actuales sobre el concepto de familia suscitaron este artículo que destacó el campo católico, específicamente a partir del periódico semanal católico O São Paulo - JOSP, órgano oficial de la Arquidiócesis paulistana, la mayor de Brasil. La investigación identificó convergencias y divergencias acerca de los posicionamientos ideológicos que trataron el concepto de "familia" con base en la comprensión e interpretación de sus publicaciones. La fuente documental fue analizada a partir de dos recortes temporales distintos, las materias vetadas por la censura previa de la dictadura militar en 1970 y las publicaciones en 2015, cuando la temática se volvió emergente en la agenda nacional. Se identificaron diferencias entre los temas y discursos de las materias en lo que se refiere a relaciones de género, matrimonio homosexual y adopción, entre otros. Sin embargo, identificamos la misma perspectiva en relación a la defensa de la composición llamada de "familia tradicional".

Palabras clave: Sociología de las Religiones, familia, dictadura militar (1964-1985), El periódico “O São Paulo". 